\title{
EL INGRESO A CUENTA POR RETRIBUCIONES EN ESPECIE DEL TRABAJO PERSONAL EN EL I.R.P.F.: POSIBLE RECUPERACION POR EL PAGADOR (Comentario a la Sentencia del T.S.J. de Murcia de 19 de junio de 1996)
}

Manuela Vega Herrero Catedrática de Derecho Financiero y Tributario

\section{CONSIDERACIONES PREVIAS Y ANTECEDENTES DE HECHO}

La vigente Ley reguladora del Impuesto sobre la Renta de las Personas Físicas, de 6 de junio de 1991, a diferencia de sus predecesoras, presta una atención especial a las retribuciones en especie, en particular a las derivadas del trabajo personal; esto se advierte en una detallada regulación de las mismas que comprende su conceptuación, enumeración -aunque no sea exhaustiva-, las reglas de valoración y mecanismo para su control.

La pretensión última de esta normativa es, sin duda, evitar que este tipo de rentas queden al margen de la tributación, como venía ocurriendo frecuentemente antes de la entrada en vigor de la citada Ley, y que, en gran medida, se debía a la inexistencia de normas específicas que dispusieran cómo debían tributar tales retribuciones, y sobre todo a la ausencia de un instrumento que permitiera a la Administración conocer la existencia, cuantía y perceptor del mentado tipo de rentas del trabajo.

Nos interesa en especial el último aspecto referido, a propósito del cual hemos de indicar que el medio arbitrado legalmente con la finalidad de controlar las retribuciones «in natura» es un ingreso a cuenta que debe ejecutar el pagador de las mismas. Dicho ingreso a cuenta se adiciona al valor de la retribución en es- 
pecie, dando lugar a un rendimiento íntegro para el perceptor ${ }^{1}$; además, como se trata de un pago a cuenta, el perceptor podrá deducirlo de la cuota líquida, obteniendo de este modo la cuota diferencial, conforme a lo previsto en al art. 83 de la Ley.

Si las consecuencias del ingreso a cuenta en la tributación de la renta del perceptor aparecen previstas legalmente en los términos descritos, no sucede lo mismo en lo que respecta al pagador. En efecto, desde la promulgación de la Ley surge un problema, objeto de múltiples consultas a la Administración, así como de frecuentes reclamaciones y recursos y que sintéticamente consiste en dilucidar si el pagador ha de asumir el importe del ingreso a cuenta o si, por contra, puede recuperarlo del perceptor; en caso de prevalecer esta segunda opción, se suscita otra cuestión adicional: cual es el método adecuado que debe utilizar el pagador para la consecución de este objetivo.

Sobre ambas cuestiones se pronuncia la Sentencia objeto del presente comentario, siendo los hechos que se someten a su consideración los siguientes:

Una entidad financiera ha concedido a un empleado un préstamo a un tipo de interés inferior al legal del dinero, dado que esto supone una retribución en especie a efectos del I.R.P.F., la entidad hace el oportuno ingreso a cuenta, procediendo posteriormente a descontar de la nómina del trabajador su importe.

El empleado considera improcedente que se le deduzca de su nómina esta cantidad e interpone reclamación ante el Tribunal Económico Administrativo Regional, que estima su pretensión. Contra esta Resolución, la entidad financiera recurre al Tribunal

1 Es preciso señalar que el art. 27 de la Ley califica al resultado como «rendimiento neto», si bien, a nuestro juicio no es correcta esta denominación y así lo hemos argumentado en nuestros trabajos «Las retribuciones en especie del trabajo personal en la nueva Ley del I.R.P.F», publicado en Estudios de Derecho Tributario (En Memoria de Maria del Carmen Bollo Arocena), Servicio Editorial de la Universidad del País Vasco, Bilbao, 1993, pág. 221 y «Retribuciones en especie del trabajo personal: valoración, rendimiento computable e ingreso a cuenta» en la obra Comentarios a la Ley del Impuesto sobre la Renta de las Personas Físicas y a la Ley del Impuesto sobre el Patrimonio (Homenaje a Luis Mateo Rodríguez), Aranzadi, Pamplona, 1995, págs. 384 y 385. 
Superior de Justicia, que dicta la Sentencia que nos ocupa, no sin antes advertir que «La cuestión planteada en este litigio consiste en determinar si puede el empresario detraer de la cantidad que satisface en metálico a sus trabajadores, lo previamente ingresado a cuenta por las retribuciones que éstos han percibido en especie».

Una vez centrado el tema y efectuadas las consideraciones imprescindibles para su mejor comprensión, haremos una breve alusión a la postura adoptada por la Administración frente a esta cuestión para acto seguido entrar en el análisis de la sentencia que se comenta.

\section{EL CRITERIO SUSTENTADO POR LA ADMINISTRA- CION TRIBUTARIA}

Como ya se ha advertido, nos encontramos ante una cuestión que empieza a plantearse al tiempo de entrada en vigor de la Ley reguladora del Impuesto provocando la formulación de varias consultas a la Administración. En las contestaciones que la Dirección General de Tributos ha dado ${ }^{2}$ se manifiesta un criterio invariable y reiterado que se concreta en dos afirmaciones: en primer término se indica que la cuantía del ingreso a cuenta constituye una mayor retribución o rendimiento del trabajo para su perceptor y en consecuencia, un mayor coste laboral a efectos de la imposición personal del pagador; se añade a continuación algo, por otra parte evidente, que «Ni la normativa legal ni reglamentaria contienen un precepto, en cuya virtud, y a efectos fiscales, pueda ser repercutido el ingreso a cuenta sobre el perceptor de la retribución en especie».

La Administración sostiene, en resumen, que el pagador no puede recuperar del perceptor el importe del ingreso a cuenta al

2 La primera que se produce es de 24 de marzo de 1992 y marca la pauta a otras posteriores, como son dos contestaciones de 14 de abril de 1992; una de estas últimas es aludida en la sentencia que se comenta y otra de 2 de julio de 1993. 
no haber una norma que le faculte para ello; la derivación lógica de esta interpretación es que el pagador ha de soportar de forma definitiva el ingreso a cuenta.

\section{TESIS JURISPRUDENCIAL}

Existen pronunciamientos de diversos Tribunales que no acatan el parecer de la administración tributaria y tratan de superar el argumento excesivamente formalista de la ausencia de norma expresa que permita al pagador recuperar lo ingresado a cuenta con motivo de las prestaciones en especie; con este objetivo razonan sobre el carácter del ingreso a cuenta para buscar una solución a esta controvertida cuestión ${ }^{3}$. En esta línea se inscribe la Sentencia que nos ocupa que, si bien sustenta una doctrina en modo alguno novedosa, la hemos seleccionado para este comentario porque argumenta con amplitud y es de fecha todavía reciente, dato éste que da idea de que nos encontramos ante un problema todavía abierto.

Con la finalidad de exponer sistemáticamente los puntos sobre los que versa este pronunciamiento, hacemos referencia en primer término a la opinión del Tribunal sobre la naturaleza del ingreso a cuenta; a este respecto se afirma «Fiscalmente, el pago a cuenta es una parte de la retribución del perceptor de las retribuciones que el pagador retiene e ingresa en el tesoro, pero la carga de dichos pagos debe ser soportada, en último término, por el trabajador...» Abundando en esta misma idea el Tribunal, compartiendo idéntico criterio que otra Sala de lo Contencioso ${ }^{4}$, asume que los ingresos a cuenta «se equiparan a los pagos a cuenta $y$, en general a las retenciones, en cuanto producen o de-

3 En el núm. 200 de Carta Tributaria se recogen la Sentencia de la Audiencia Nacional de 15 de noviembre de 1993 y varias Resoluciones de los tribunales Económico Administrativos Regionales que constituyen claros ejemplos de lo referido en el texto.

4 Concretamente la de Asturias en Sentencia de 23 de marzo de 1995. 
ben producir el mismo efecto, el descuento o merma del patrimonio de los perceptores de la renta de las cantidades correspondientes».

Todo ello lo deduce el tribunal de un razonamiento previo cual es que «el deudor de la obligación tributaria material, sujeto pasivo sobre el que incide el Impuesto, es el trabajador, pues el empresario solo asume la obligación accesoria e instrumental de ingresar el pago a cuenta, pero no es el titular de la carga tributaria derivada de la obligación principal».

Enjuiciando el parecer del Tribunal expuesto hasta el momento, nos parece acertado el paralelismo que se establece entre el ingreso a cuenta y otros pagos a cuenta, especialmente las retenciones que son las más relevantes entre aquellos; es indudable que se trata de institutos que cumplen una función similar, es decir, el control de los rendimientos del perceptor. También tienen parecida repercusión en la imposición del perceptor pues tanto las retenciones como los ingresos a cuenta conforman el rendimiento íntegro y se deducen de la cuota líquida. Ahora bien, en el caso de las retenciones su importe lo soporta el perceptor de retribuciones dinerarias ya que es consustancial al sustituto retenedor detraer el impuesto cuando realice pagos al contribuyente. En cambio, en el caso que nos ocupa no se puede detraer nada porque es inviable hacerlo de una prestación en especie ${ }^{5}$; por ello precisamente se establece un mecanismo diverso a las retenciones, el ingreso a cuenta, que si bien tiene idéntico objetivo y un funcionamiento similar a aquellas, difiere en la falta de una previsión tributaria sobre el modo de resarcirse por el pagador, recuperando el importe ingresado del perceptor o contribuyente que a nuestro juicio, y aquí si coincidimos con la doctrina de la Sala, es quien debe asumirlo ya que es un gravamen sobre su renta ${ }^{6}$.

5 En nuestro trabajo «Las retribuciones en especie del trabajo personal en la nueva Ley del I.R.P.F.», ya citado, hemos discurrido ampliamente sobre la incompatibilidad entre el instituto de la retención y las retribuciones en especie (págs. 221 y 222).

6 La misma opinión apoyada en diversos razonamientos, hemos mantenido en nuestra publicación: «Retribuciones en especie del trabajo personal; valoración, rendimiento computable e ingreso a cuenta». 
Una vez admitida la procedencia del resarcimiento que corresponde al pagador, o lo que es igual, a quien entrega el bien, derecho o servicio en que se concreta la retribución en especie, la sentencia se manifiesta sobre el modo en que pueda llevarse a cabo dicho resarcimiento.

A este respecto, el criterio que se adopta es muy amplio pues se dice textualmente que «con el fin de evitar un posible enriquecimiento injusto, que el mismo (el resarcimiento) pueda realizarse por cualquiera de los modos permitidos en el ordenamiento, y naturalmente, entre ellos, por el pacto entre las partes que permita hacer el descuento en la nómina del trabajador».

Con esta solución se respalda la actuación del pagador que procedió a descontar el ingreso a cuenta de la nómina del empleado; es ésta, sin duda, la vía más cómoda y lógica de conseguir recuperar lo ingresado a cuenta. No obstante, el Tribunal está abierto a otras posibles formas y, desde luego, habrá supuestos en que no sea factible la detracción de retribución dineraria; piénsese en un caso extremo en que la retribución sea en su totalidad en especie.

No obstante, y compartiendo con el Tribunal la necesidad del resarcimiento, nos parece que debe ser una norma tributaria la que afronte esta cuestión ya que, en definitiva, la obligación de hacer el ingreso a cuenta es una obligación tributaria y normas de esta misma naturaleza regulan la incidencia del ingreso a cuenta en la renta del perceptor. Es cierto que la inhibición de la normativa tributaria puede paliarse mediante el contrato laboral pero, a nuestro juicio, este problema requiere una solución expresa que, por otra parte, evitaría litigios y aportaría certeza al modo de proceder del pagador. 